\title{
Renal enlargement and insulin-like growth factor-1 accumulation in the Wistar rat model of experimental diabetes is not prevented by angiotensin converting enzyme inhibition
}

\author{
J.P. New ${ }^{1}$, J.P. Canavan ${ }^{1}$, A. Flyvbjerg ${ }^{2}$, G. Hamon ${ }^{3}$, R. W. Bilous ${ }^{4}$, S. M. Marshall ${ }^{1}$ \\ ${ }^{1}$ Department of Medicine, University of Newcastle upon Tyne, Newcastle upon Tyne, UK \\ ${ }^{2}$ Institute of Experimental Clinical Research, University of Aarhus, Aarhus, Denmark \\ ${ }^{3}$ Roussel Uclaf, Paris, France \\ ${ }^{4}$ Diabetes Care Centre, Middlesbrough General Hospital, Middlesbrough, UK
}

Summary Experimental diabetes is associated with renal enlargement and glomerular hyperfiltration. Possible mechanisms for these changes could be the direct effects of growth factors such as insulin-like growth factor-1 and angiotensin II. We investigated whether treatment with trandolapril, an angiotensin converting enzyme inhibitor, prevented renal enlargement in streptozotocin-diabetic rats. Seven groups of male Wistar rats were studied: $\mathrm{C}$ (control + placebo); CL (control + low-dose trandolapril, $0.01 \mathrm{mg} \cdot \mathrm{kg}^{-1} \cdot$ day $^{-1}$ ); $\mathrm{CH}$ (control + high-dose trandolapril, $0.5 \mathrm{mg} \cdot \mathrm{kg}^{-1} \cdot$ day $^{-1}$ ); DP (diabetic + placebo); DI (diabetic, insulin-treated); DL (diabetic + low-dose trandolapril); DH (diabetic + highdose trandolapril) and DI (diabetic + insulin). From day 2 glucose concentrations and body weight were similar in the non-diabetic and diabetic animals treated with insulin. Diabetic animals treated with placebo and low-dose trandolapril weighed significantly less compared to the control group. The diabetic groups, not treated with insulin, showed marked hyperglycaemia throughout the study. Kidney weight was greater in the diabetic, non insulin-treated groups compared with the control and insulin-treated groups. After $24 \mathrm{~h}$ of diabetes, kidney insulin-like growth factor-1 content was significantly increased from baseline levels in groups DP, DL and DH but by $48 \mathrm{~h}$ these levels had returned to normal. Renal tissue angiotensin converting enzyme activity was similar in groups $\mathrm{C}$ and DI but significantly reduced in all trandolapril-treated animals. Despite inhibiting renal angiotensin converting enzyme activity renal enlargement with increased tissue insulin-like growth factor-1 still occurred. This suggests that neither angiotensin II nor glomerular hyperfiltration, with raised intraglomerular pressure, play a role in the initial renal enlargement seen in experimental diabetes. Renal accumulation of insulin-like growth factor-1 appears to be an important factor in early renal hypertrophy and its effects are not modulated by angiotensin converting enzyme or angiotensin II. [Diabetologia (1996) 39: 166-171]

Key words Renal enlargement, renal haemodynamics, angiotensin II, insulin-like growth factor-1, angiotensin converting enzyme inhibition.
Renal hypertrophy and hyperfiltration are characteristic, well-described early findings in experimental diabetes. The causative mechanisms are unknown. Glomerular hyperfiltration, with increased intra-

Received: 4 May 1995 and in revised form: 22 August 1995

Corresponding author: Dr. J.P. New, Manny Cussins Centre, St James's University Hospital, Leeds LS9 7TF, UK

Abbreviations: ACE, Angiotensin converting enzyme; IGF-1, insulin-like growth factor-1; $\mathrm{Na}^{+} / \mathrm{H}^{+}$exchange, sodium hydrogen exchange; RPF, renal plasma flow; GFR, glomerular filtration rate. glomerular pressure, has been implicated in the initiation and progression of diabetic nephropathy [1-3], the renal hypertrophy being a compensatory change attempting to normalise the glomerular filtration rate (GFR) and intraglomerular pressure. This suggests that increased single nephron GFR, leading to glomerular hyperfiltration, per se stimulates renal hypertrophy $[4,5]$. The initial renal growth observed in experimental diabetes or after surgical ablation of renal tissue is preceded by an increase in renal tissue insulin-like growth factor 1 (IGF-1) concentration implying a (patho)physiologi-cal role for growth factors 
$[6,7]$. Acute infusion of IGF- 1 causes an acute increase in renal plasma flow (RPF) and GFR which could be a further stimulus to renal hypertrophy [8$10]$.

Our hypothesis is that hyperglycaemia causes increases in IGF-1 leading to increases in RPF, GFR and intraglomerular pressure. If raised intraglomerular pressure is the main stimulus for renal enlargement then treatment with angiotensin converting enzyme (ACE) inhibitors, which will normalise intraglomerular pressure, should prevent renal enlargement independent of the accumulation of IGF-1. To examine this hypothesis we investigated the effects of trandolapril, a long-acting ACE inhibitor which strongly inhibits tissue ACE, on renal enlargement during the first week of experimental diabetes. Two doses of trandolapril were used; a low dose which would reduce intraglomerular pressure with little reduction in systemic arterial pressure; and a higher dose which reduced systemic arterial pressure.

\section{Materials and methods}

Animals. Male Wistar rats bred by the Comparative Biology Centre (University of Newcastle upon Tyne), with a body weight of $182 \pm 1.1 \mathrm{~g}$ (mean \pm SEM) were studied. Diabetes was induced by i. v. injection of streptozotocin ( $\mathrm{pH} \mathrm{4.0)}$ (Sigma, Poole, Dorset, UK) in a dose of $55 \mathrm{mg} \cdot \mathrm{kg}^{-1}$ body weight on day 0 . All animals were weighed, had tail vein blood glucose measured (One Touch II; Lifescan, Johnson and Johnson, High Wycombe, Bucks., UK), and urinalysis for glucose and ketones (Keto Diastix; Bayer Diagnostics, Stoke Poges, UK) was performed on a daily basis. Rats were housed six to a cage in a room with a $12: 12 \mathrm{~h}(07.00-19.00$ hours $)$ artificial light cycle, temperature $21 \pm 2{ }^{\circ} \mathrm{C}$ and humidity $50 \pm 4 \%$. The animals had free access to water throughout the experiment. Three days before commencing the study the animals were matched for body weight and randomized into seven groups:

$C$, non-diabetic, placebo treated

CL, non-diabetic, low-dose trandolapril

$(n=19)$

$\mathrm{CH}$, non-diabetic, high-dose trandolapril

$(n=20)$

$(n=20)$

DP, diabetic, placebo treated

$(n=37)$

$\mathrm{DL}$, diabetic, low-dose trandolapril

$\mathrm{DH}$, diabetic, high-dose trandolapril

DI, diabetic, placebo, insulin

$(n=34)$

$(n=35)$

$(n=22)$

Previous studies showed that high-dose trandolapril (Roussel UCLAF, Paris, France) $0.5 \mathrm{mg} \cdot \mathrm{kg}^{-1} \cdot \mathrm{day}^{-1}$ suppressed renal tissue ACE activity by $96 \%$ and reduced the rise in systolic blood pressure following the induction of diabetes by $20 \%$ (29 mmHg), while the low-dose trandolapril, $0.01 \mathrm{mg}$. $\mathrm{kg}^{-1}$. day ${ }^{-1}$, suppressed renal tissue ACE activity by $86 \%$ and reduced the rise in systolic blood pressure by $14 \%$ (21 mmHg). Trandolapril or placebo (solvent, $1 \mathrm{mmol} \mathrm{1^{-1 }}$. $\mathrm{NaOH}$ solution) was injected s.c. daily. Animals in group DI were given 8 units of IU40 long-acting heat-treated ultralente insulin (Novo Nordisk, Copenhagen, Denmark) on day 0. Thereafter, the dose was adjusted daily, according to blood glucose concentration, to maintain normoglycaemia. Insulin, trandolapril and placebo treatments commenced immediately after injection of streptozotocin. On day 0 ten untreated animals were killed. Under halothane anaesthesia blood was removed by cardiac puncture, cervical dislocation was performed and both kidneys were rapidly removed, then divided into two sections (upper and lower); all sections were weighed, then wrapped in tin foil and snap-dried in liquid nitrogen. Tissue was stored at $-70^{\circ} \mathrm{C}$ until tissue protein, IGF-1 and ACE activity were determined. On day 1 animals from groups D, DL, and DH were killed, whilst on days 2, 4 and 7 animals from all groups were killed. Serum and plasma were stored at $-40^{\circ} \mathrm{C}$ before analysis of IGF-1 and renin activity.

Protein determination. The left lower kidney section was homogenised in $2 \mathrm{~mol} \cdot \mathrm{l}^{-1} \mathrm{NaOH}$ and the protein content determined using the method of Lowry et al. [11] on an automated Cobas Bio machine (Roche, Welwyn Garden City, Herts., UK).

IGF-I and ACE determination. The right lower kidney sections were homogenized in $1 \mathrm{~mol} \cdot \mathrm{I}^{-1}$ acetic acid in an ice bath $(5 \mathrm{ml}$ acetic acid/1000 mg tissue). The tissue was extracted twice and, after lyophilization, samples were re-dissolved in $40 \mathrm{mmol} \cdot 1^{-1}$ phosphate buffer ( $\mathrm{pH} 8.0$ ). Tissue extracts were kept at $-20^{\circ} \mathrm{C}$ until IGF-1 assay was performed in dilute extracts (1:60). IGF-1 was determined by radioimmunoassay using a polyclonal IGF-1 antibody (Nichols Institute Diagnostics, San Juan Capistrano, Calif., USA). The intra-assay coefficient of variation was $5.4 \%$ and inter-assay was $9.3 \%$.

Renal tissue ACE activity was measured using a radiometric assay [12] and plasma renin measured using a radioimmunoassay.

\section{Statistical analysis}

The data are expressed as the mean \pm SEM unless otherwise stated. Analysis between groups was carried out by one-way analysis of variance and significant differences tested using unpaired $t$-tests or a Mann-Whitney test as appropriate, corrected for multiple comparisons using the Bonferroni method.

\section{Results}

Blood glucose and body weight (Figs. 1 and 2). All animals given streptozotocin developed diabetes; mean blood glucose concentration was $14.1 \pm 1.1 \mathrm{mmol} \cdot \mathrm{l}^{-1}$ after $24 \mathrm{~h}$. Blood glucose level in the groups DP, DL and DH was more than $15 \mathrm{mmol} \cdot \mathrm{l}^{-1}$ after $24 \mathrm{~h}$ and remained significantly raised to a similar extent in these three groups throughout the study $(p<0.001$ compared to C), whilst in the insulin-treated group (DI) blood glucose level was comparable to that of the control group from day 2 until day 7. Groups DP, DL and $\mathrm{DH}$ failed to gain weight for the first $48 \mathrm{~h}$. Thereafter, weight gain paralleled that of the control group although at all time points body weight remained lower in the diabetic animals. The insulin-treated diabetic animals did not lose weight and their weight gain was similar to the non-diabetic, placebo, low-dose and high-dose trandolapril-treated animals.

Kidney growth and protein content (Fig. 3). Kidney weight in groups DP, DL and DH was greater than group $\mathrm{C}$ from day 2 until day 7 . On day 7 kidney 


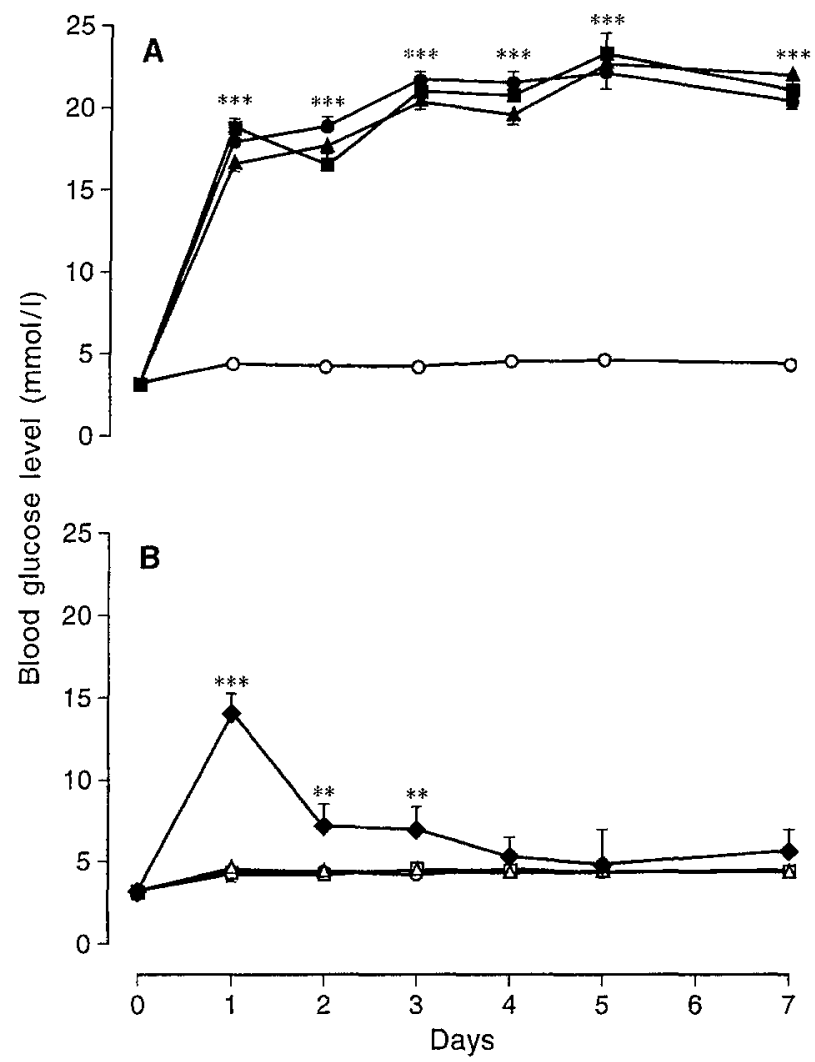

Fig.1A, B. Blood glucose levels $\left(\mathrm{mmol} \cdot 1^{-1}\right.$ ) in $(\mathbf{A})$ control animals, $\mathrm{C}(\mathrm{O})$; diabetic, placebo, DP (O); diabetic, low-dose trandolapril, DL ( $\mathbf{A})$; diabetic, high-dose trandolapril, DH (W); and (B) control, C (O); control, low-dose trandolapril, $\mathrm{CL}(\triangle)$; control, high-dose trandolapril, $\mathrm{CH}(\square)$; diabetic, insulin-treated, DI $(\bullet)$. Values are mean \pm SEM. $* * p<0.01$ compared to control; *** $p<0.001$ for DL, DH and DP compared to control

weight in all three diabetic groups not treated with insulin was similar to but greater than of all non-diabetic groups (790 $\pm 28 \mathrm{mg} \mathrm{C} ; 1100 \pm 30 \mathrm{DP} ; 1010 \pm 30$ $\mathrm{DL}$ and $1070 \pm 50 \mathrm{DH})$. Kidney weight in DI was similar to C (C $790 \pm 28$ vs DI $800 \pm 43 \mathrm{mg}$ ). Protein concentration was similar in all groups on all days.

Renal ACE activity and plasma renin activity. Figure 4 shows the changes in renal tissue ACE activity and Figure 5 the plasma day 7 renin levels. Treatment with both low- and high-dose trandolapril virtually abolished tissue ACE activity within $24 \mathrm{~h}$. This was accompanied by an appropriate rise in plasma renin. Groups C and DI had comparable renal ACE activity throughout the study.

Renal IGF-1. On day 1 renal IGF-1 had risen to a similar extent in groups DP $\left(514 \pm 62 \mathrm{ng} \cdot \mathrm{g}^{-1}\right)$, DL $\left(427 \pm 40 \mathrm{ng} \cdot \mathrm{g}^{-1}\right)$ and $\mathrm{DH}\left(419 \pm 29 \mathrm{ng} \cdot \mathrm{g}^{-1}\right)$, all significantly higher than the basal concentration $\left(312 \pm 38 \mathrm{ng} \cdot \mathrm{g}^{-1}, p<0.01\right.$ for all). By day 2 , tissue IGF-1 concentration had returned to the baseline levels in these groups and did not differ from the control animals for the remainder of the study. No rise in

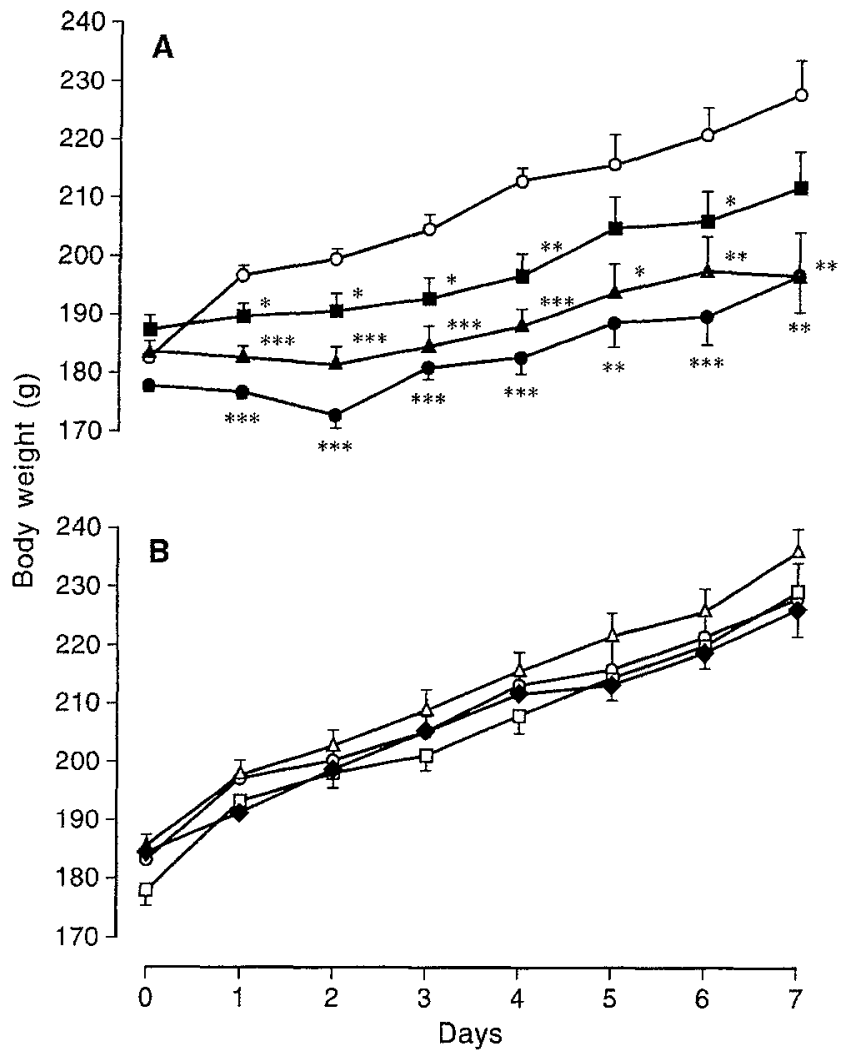

Fig. 2. A Body weight (g) in control animals, $(\mathrm{O})$; diabetic, placebo (O); diabetic, low-dose trandolapril $(\boldsymbol{A})$; diabetic, high-dose trandolapril $(\square)$; B control animals, $(O)$; control, low-dose trandolapril $(\triangle)$; control, high-dose trandolapril $(\square)$; and diabetic, insulin-treated $(\bullet)$. Values are mean \pm SEM. *** $p<0.001$ compared to control; ** $p<0.01$ compared to control; * $\mathrm{p}<0.05$ compared to control

IGF-1 concentration above baseline was seen in groups DI, C, CL and $\mathrm{CH}$.

\section{Discussion}

We have shown that in this model of experimental diabetes, despite adequate tissue ACE inhibition, renal enlargement and early accumulation of IGF-1 still occurred. This suggests that angiotensin II is not involved in early renal enlargement. Furthermore, as ACE inhibition would reduce intraglomerular pressure [13-15] this suggests that renal growth does not occur secondary to changes in renal haemodynamics and is therefore independent of renal functional changes.

It is well-established that experimental diabetes causes a marked increase in renal size within $48-72 \mathrm{~h}$ [16-18], with increases in RNA, DNA and protein content implying renal growth. Renal growth is dependent upon glycaemic control and is most striking at moderate levels of hyperglycaemia (glucose 15$\left.25 \mathrm{mmol} \cdot \mathrm{l}^{-1}\right)[17-19]$. Renal enlargement is associated with increased glomerular volume and tubular 


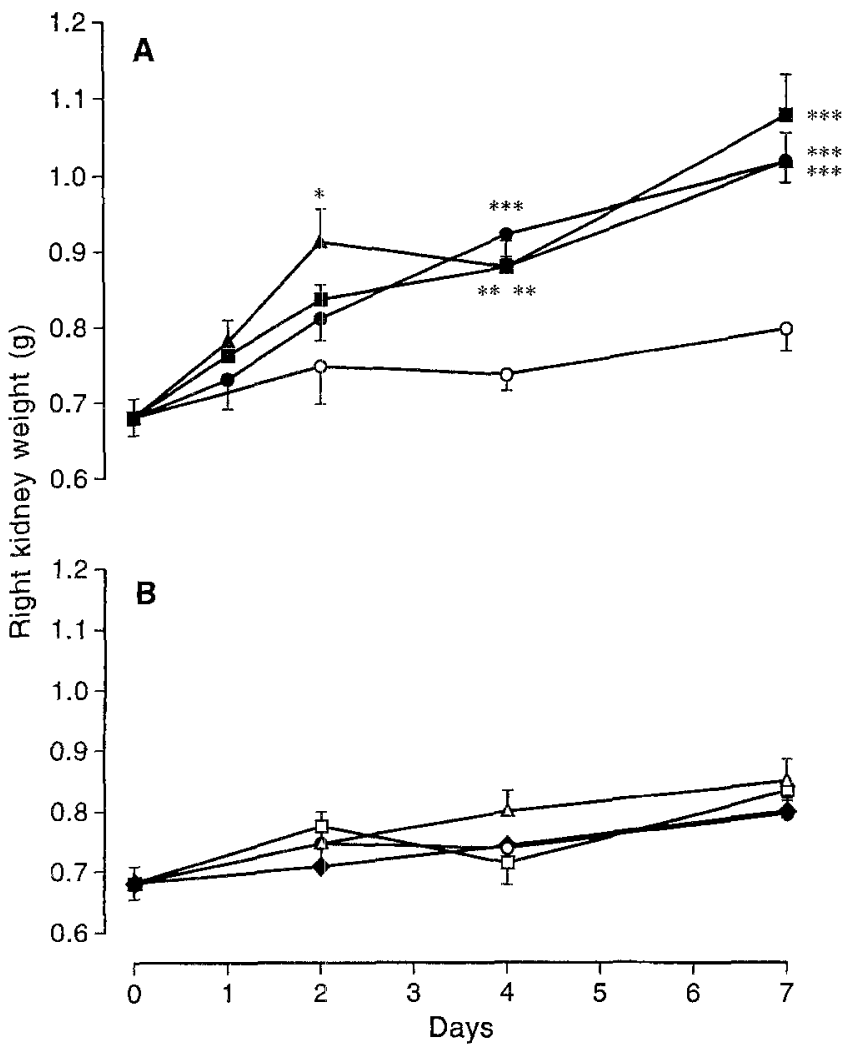

Fig. 3A, B. Right kidney, wet weight (g) in (A) control animals $(\mathrm{O})$; diabetic, placebo (O); diabetic, low-dose trandolapril (A); diabetic, high-dose trandolapril $(\square)$; and (B) control $(\bigcirc)$; control, low-dose trandolapril $(\triangle)$; control, high-dose trandolapril $(\square)$; diabetic, insulin-treated animals. Values are mean \pm SEM. $* * * *<0.001$ compared to control; ** $p<0.01$ compared to control; * $p<0.05$ compared to control

hypertrophy $[19,20]$, and is preceded by a transient rise in renal tissue IGF-1 content, which reaches a peak $24-48 \mathrm{~h}$ after the induction of diabetes $[6,7]$ and returns to basal levels within 4 days as seen in groups DP, DL and DH. These changes precede increases in kidney RNA, protein, function and size $[6$, $16,21]$. Kidney IGF-1 accumulation parallels thymidine incorporation in renal tubules [22], suggesting a local mitogenic effect of IGF-1. Infusion of IGF-1 in non-diabetic rats causes renal enlargement [10]. If IGF-1 is infused in diabetic rats, 5 days after induction of diabetes when endogenous IGF-1 would have returned to normal levels, there is sustained renal growth [23]. Diabetic animals treated with insulin in order to maintain normoglycaemia show no rise in renal IGF-1 or increase in renal size. Octreotide also inhibits renal IGF-1 accumulation and renal enlargement in experimental diabetes in the short term and reduces the increase in albumin excretion seen in non-diabetic rats with increasing age [24]. These studies demonstrate that rises in endogenous or exogenous IGF-1 are required for renal enlargement suggesting that IGF-1 acts as a growth factor. How IGF1 acts as a growth factor is unclear but stimulation of intracellular $\mathrm{Na}^{+} / \mathrm{H}^{+}$exchange has been suggested

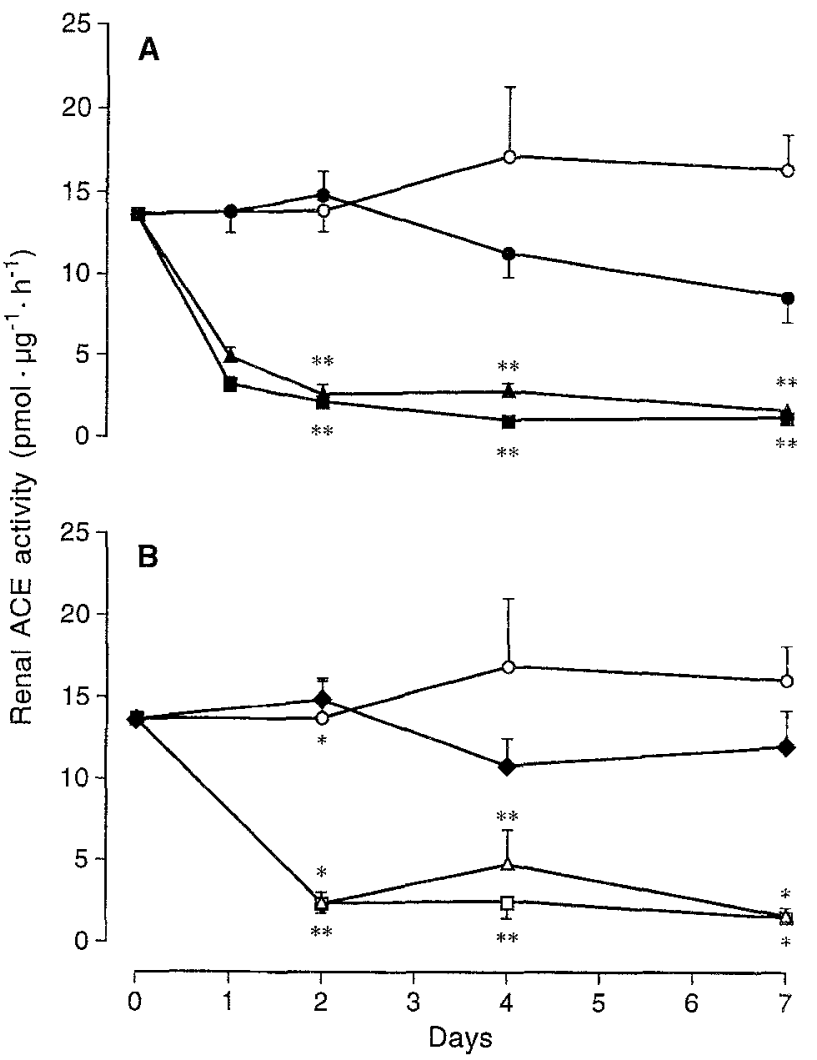

Fig. 4A, B. Renal tissue ACE activity $\left(\mathrm{pmol} \cdot \mu_{\mathrm{g}} \mathrm{g}^{-1} \cdot \mathrm{h}^{-1}\right)$ in (A) control animals $(\bigcirc)$; diabetic, placebo $(\mathbf{O})$; diabetic, low-dose trandolapril $(\mathbf{\Delta})$; diabetic, high-dose trandolapril $(\boldsymbol{\square})$; and (B) control $(\bigcirc)$; control, low-dose trandolapril $(\triangle)$; control, high-dose trandolapril $(\square)$; diabetic, insulin-treated animals $(\bullet)$. Values are mean \pm SEM. ${ }^{* *} p<0.01$ compared to control; ${ }^{*} p<0.05$ compared to control

[25]. Angiotensin II also stimulates $\mathrm{Na}^{+} / \mathrm{H}^{+}$exchange [26] and could theoretically modulate the growth-promoting effects of IGF-1.

Other work in experimental diabetes has shown that both short- and long-term (>1year) treatment with the ACE inhibitors captopril or enalapril reduce intraglomerular pressure, GFR and single nephron GFR $[13,15]$. Furthermore, treatment with ACE inhibition also prevented glomerular basement membrane thickening [27], glomerular sclerosis [13] and reduced the rise in urinary albumin excretion $[13,15,27$, 28 ]. It is noteworthy that despite these apparently beneficial effects wet kidney weight increased in all these studies. It is possible that different cell types within the kidney respond differently to the metabolic effects of diabetes and to ACE inhibition, so that while ACE inhibition prevents basement membrane thickening it may not prevent changes in glomerular volume or tubular growth. Zatz et al. [15] demonstrated a lesser rise in wet kidney weight in those diabetic rats treated with enalapril compared to the diabetic placebo-treated rats; however kidney weight was significantly increased compared to the control group $(p<0.05)$.

Thus, despite almost complete inhibition of renal ACE activity, and presumably reduction of intraglom- 


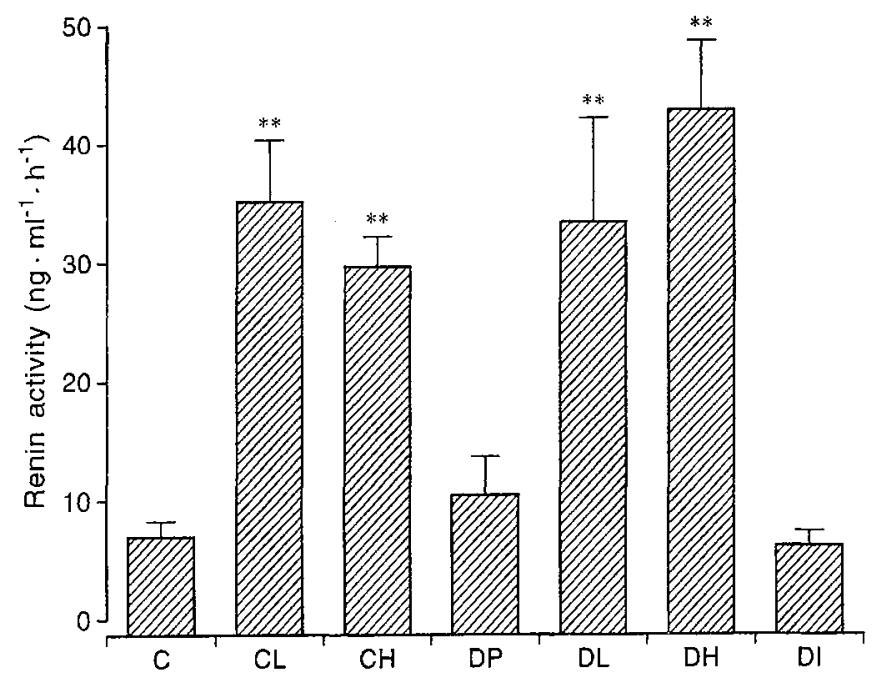

Fig.5. Day 7 serum renin levels $\left(\mathrm{ng} \cdot \mathrm{ml}^{-1} \cdot \mathrm{h}^{-1}\right)$ in control animals (C); control, low-dose trandolapril (CL); control, highdose trandolapril (CH); diabetic, placebo (DP); diabetic, lowdose trandolapril (DL); diabetic, high-dose trandolapril (DH) and diabetic, insulin-treated animals (DI). Values are mean \pm SEM. ${ }^{* *} p<0.01$ compared to control

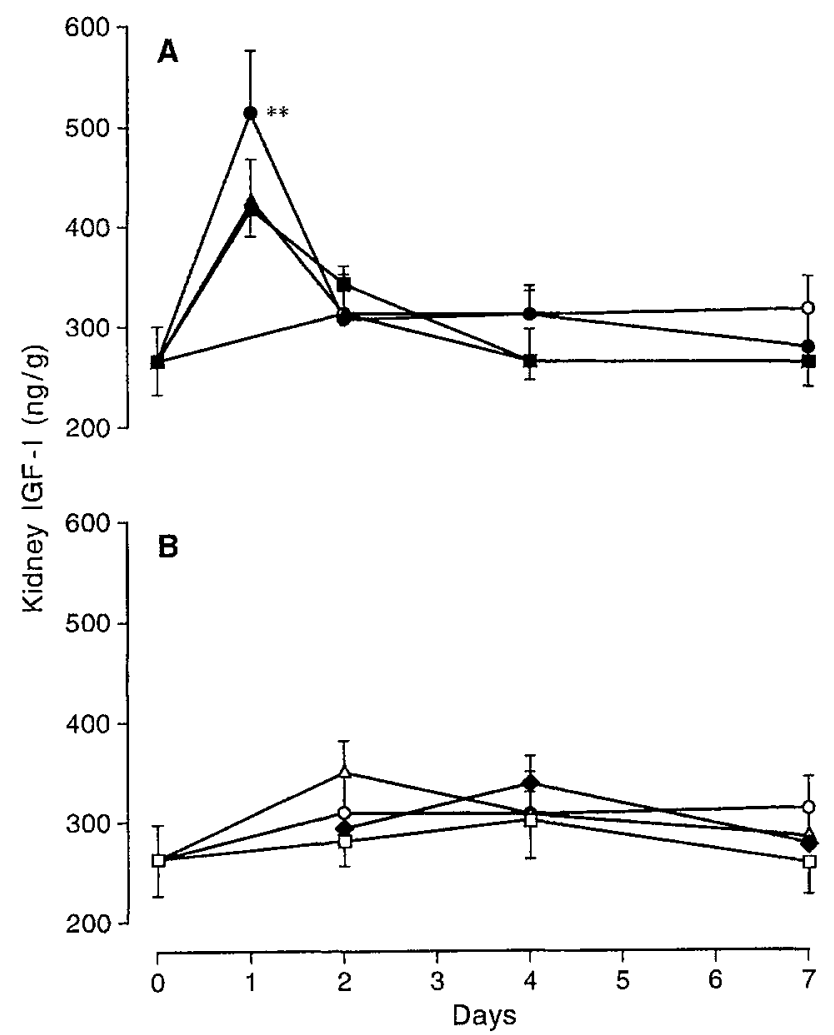

Fig. 6A, B. Renal tissue IGF-1 concentration (ng $\cdot \mathrm{g}^{-1}$ ) in $\mathbf{A}$ control animals $(O)$; diabetic, placebo $(\mathbf{O})$; diabetic, low-dose trandolapril $(\boldsymbol{\Delta})$; diabetic, high-dose trandolapril $(\boldsymbol{\square})$; and (B) control $(\bigcirc)$; control, low-dose trandolapril $(\Delta)$; control, high-dose trandolapril $(\square)$; and diabetic, insulin-treated animals $(\bullet)$. Values are mean \pm SEM. $* * p<0.01$ compared to baseline IGF-1 concentrations for groups: diabetic, placebo; diabetic, low-dose trandolapril and diabetic, high-dose trandolapril erular pressure, accumulation of IGF-1 and renal enlargement still occur. This suggests that neither angiotensin II nor alterations in the renal haemodynamic abnormalities of glomerular hyperfiltration and raised intraglomerular pressure play a role in the initial renal enlargement seen in experimental diabetes. Renal accumulation of IGF-1 appears to be an important factor in early renal hypertrophy and its effects are not modulated by ACE or angiotensin II.

Acknowledgements. We thank the staff of the Comparative Biology Centre, Newcastle upon Tyne, for their help in breeding and caring for the animals. We would like to specially thank Ms. C. Burn and Ms. K. Nyborg for their excellent technical help. We are indebted to Dr. C. Chevillard and Dr. S. Jouqueys (Roussel Uclaf, INSERM, Montpellier, France) for measuring the tissue ACE and plasma renin activities. This study was supported by grants from Roussel Uclaf, the Novo Foundation, the Danish Diabetes Foundation and the Danish Medical Research Council.

\section{References}

1. Hostetter TH, Rennke HG, Brenner BM (1982) The case for intrarenal hypertension in the initiation and progression of diabetic and other glomerulopathies. Am J Med 72: $375-380$

2. Zatz R, Brenner BM (1986) Pathogenesis of diabetic microangiopathy. The haemodynamic view. Am J Med 80 : $443-453$

3. Zatz R, Meyer T, Rennke H, Brenner BM (1985) Predominance of haemodynamic rather than metabolic factors in the pathogenesis of diabetic glomerulopathy. Proc Natl Acad Sci USA 82: 5963-5967

4. Hostetter TH, Troy JL, Brenner BM (1981) Glomerular haemodynamics in experimental diabetes. Kidney Int 19: 410-415

5. Hostetter TH, Olson JL, Rennke HG, Venkatachalam MA, Brenner BM (1981) Hyperfiltration in remnant nephrons: a potential adverse response to renal ablation. Am J Physiol 241:F85-F93

6. Flyvbjerg A, Thorlacius-Ussing O, Naeraa R, Ingerslev J, Ørskov H (1988) Kidney tissue somatomedin C and initial renal growth in diabetic and uninephrectomised rats. Diabetologia 31 : $310-314$

7. Flyvbjerg A, Bornfeldt KE, Marshall SM, Arnqvist $\mathrm{HJ}$, Ørskov H (1990) Kidney IGF-1 mRNA in initial renal hypertrophy in experimental diabetes in rats. Diabetologia 33: 334-338

8. Hirschberg R, Kopple JD (1989) Evidence that insulin-like growth factor 1 increases renal plasma flow and glomerular filtration rate in fasted rats. J Clin Invest 83: 326-330

9. Hirschberg R, Kopple JD, Blantz R, Tucker B (1991) Effects of recombinant human insulin-like growth factor on glomerular dynamics in the rat. J Clin Invest 87: 1200-1206

10. Guler HP, Schmid C, Zapf J, Froesch ER (1989) Effects of recombinant insulin-like growth factor 1 on insulin secretion and renal function in normal human subjects. Proc Natl Acad Sci USA 86: 2868-2872

11. Lowry OH, Rosebrough NJ, Farr AL, Randall RJ (1951) Porcine measurements with the folin phenol reagents. J Biol Chem 193: 265-275

12. Chevillard C, Saavedra JM (1982) Distribution of angiotensin converting enzyme activity in specific areas of the rat brain stem. J Neurochem 38: 281-284 
13. Anderson S, Rennke H, Garcia D, Brenner BM (1989) Short and long term antihypertensive therapy in the diabetic rat. Kidney Int 36:526-536

14. Anderson S, Rennke HG, Brenner BM (1986) In arresting renal disease, all anti-hypertensive drugs are not created equal. Kidney Int 29: 314 (Abstract)

15. Zatz R, Dunn BR, Meyer TW, Anderson S, Rennke HG, Brenner BM (1986) Prevention of diabetic glomerulopathy by pharmacological amelioration of glomerular capillary hypertension. J Clin Invest 77: 1925-1930

16. Seyer-Hansen K (1976) Renal hypertrophy in streptozotocin-diabetic rats. Clin Sci 51: 551-555

17. Seyer-Hansen K (1977) Renal hypertrophy in experimental diabetes: relation to severity of diabetes. Diabetologia 13: 141-143

18. Seyer-Hansen K (1983) Renal hypertrophy in experimental diabetes. Kidney Int 23: 643-646

19. Rasch R (1979) Prevention of diabetic glomerulopathy in streptozotocin diabetic rats by insulin treatment. Diabetologia 16: 319-324

20. Rasch R (1984) Tubular lesions in streptozotocin-diabetic rats. Diabetologia 27: $32-37$

21. Cortes P, Dumler F, Goldman J, Lewin NW (1987) Relationship between renal function and metabolic alterations in early streptozotocin-induced diabetes in rats. Diabetes 36: $80-87$
22. Rasch R, Rytter-Nørgaard JO (1983) Renal enlargement: comparative autoradiographic studies of ${ }^{3} \mathrm{H}$-thymidine uptake in diabetic and uninephrectomized rats. Diabetologia 25: $280-287$

23. Flyvbjerg A, Bornfeldt KE, Ørskov H, Arnquist HJ (1991) Effect of insulin-like growth factor 1 infusion on renal hypertrophy in experimental diabetes mellitus in rats. Diabetologia 34: $715-720$

24. Flyvbjerg A, Marshall SM, Frystyk J, Hansen KW, Harris AG, Ørskov H (1992) Octreotide administration in diabetic rats: effects on kidney growth and urinary albumin excretion. Kidney Int 41: 805-812

25. Lever AF (1986) Slow pressor mechanisms in hypertension: a role for hypertrophy of resistance vessels? J Hypertension 4: 515-524

26. Brock TA, Lewis LJ, Smith BJ (1982) Angiotensin increases $\mathrm{Na}^{+}$entry and $\mathrm{Na}^{+} / \mathrm{H}^{+}$pump activity in cultures of smooth muscle from rat aorta. Proc Natl Acad Sci USA 79: $1438-1442$

27. Cooper ME, Allen TJ, Clarke BE, Jerums G, Doyle AE (1989) Enalapril retards glomerular basement thickening and albuminuria in the diabetic rat. Diabetologia 32: 326328

28. O'Brian R, Cooper ME, Jerums G, Doyle AE (1993) The effects of perindopril and triple therapy in a normotensive model of diabetic nephropathy. Diabetes 42: 604-609 